\title{
Behavioral Pediatrics: A Team-Based Interprofessional Approach
}

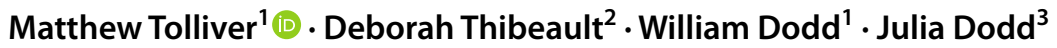 \\ Accepted: 5 January 2022 / Published online: 12 February 2022 \\ (c) The Author(s), under exclusive licence to Springer Science+Business Media, LLC, part of Springer Nature 2022
}

\begin{abstract}
An interprofessional approach to pediatric behavioral care is increasingly important in the care of pediatric patients, who present to healthcare settings with a wide variety of concerns ranging from potty training to depression. Previously, much of the care of these patients have focused on a narrow approach to the problem, based on the expertise of the professional providing care. Faculty from three disciplines: Social Work, Psychology, and Medicine collaborated to design a course for students from these three disciplines to collaborate in attaining three goals: (1) reinforce the importance of multidisciplinary collaboration, (2) share clinical techniques and skills in a simulated interprofessional setting, and (3) practice collaboration within interprofessional teams. We detail the course goals and design and topics covered and discuss implementation of this course. Suggested module content and pedagogical design are discussed, and case examples are detailed with the goal of encouraging the adoption of similar courses.
\end{abstract}

Keywords Interprofessional education $\cdot$ Pediatrics $\cdot$ Course design $\cdot$ Multidisciplinary $\cdot$ Training

\section{Background}

An integrated and interprofessional approach to treating pediatric behavioral health concerns in primary care has been associated with increased access to and quality of behavioral healthcare, improved behavioral health outcomes, decreased cost to care, and strong provider satisfaction (Asarnow et al., 2015; Hine et al., 2017; Walter et al., 2019). These concerns, which range from depression to potty training, are incredibly common in pediatric settings (Polaha et al., 2011; Williams et al., 2004), but can be time consuming for physicians to address alone. An integrated approach to care is consistent with the movement toward Primary Care Medical Homes and efforts to achieve the Quadruple Aim in healthcare (Bodenheimer \& Sinsky, 2014) of improving the patient experience, reducing costs, addressing the health needs of populations, and improving the job

Matthew Tolliver

tolliverr@etsu.edu

1 Department of Pediatrics, East Tennessee State University, 325 N State of Franklin Rd, Johnson City, TN 37604, USA

2 Department of Social Work, East Tennessee State University, Johnson City, TN, USA

3 Department of Psychology, East Tennessee State University, Johnson City, TN, USA satisfaction of healthcare providers. Additionally, such an approach has the potential to address social determinants of health (Sokol et al., 2019).

Despite the positive potential of integrated care, many of the professions that may eventually provide the bulk of these behavioral health services do not receive in-depth training in treating these behavioral presentations (e.g., McMillan et al., 2017) and further do not receive training on working as an effective member of an interprofessional team in pediatrics. To address this gap in training and in response to a university call for novel curriculum development in interprofessional education, the authors (representing three different professions and university departments) designed and implemented an interprofessional course in Behavioral Pediatrics with students from medicine, clinical psychology, and clinical social work.

\section{ETSU's Commitment to Interprofessional Education}

East Tennessee State University (ETSU) is a public university located in Johnson City, Tennessee, a mid-metropolitan area in southern Appalachia. ETSU has a strong commitment to interprofessional education (IPE), with collaboration across the Academic Health Science Center Colleges of 
Medicine, Pharmacy, Nursing, Public, Health, and Clinical Rehabilitative Sciences, as well as Departments of Psychology and Social Work (Polaha et al., 2019). A state-of-theart Interprofessional Education Research Center (IPERC) houses advanced simulation labs, classrooms, research, and study space to support the program and is the hub that facilitates the university's Interprofessional Education Program (IPEP), a 2-year longitudinal experience for learners. IPEP consists of both group-based didactic and experiential components focused on teaching the Interprofessional Education Collaborative's Core Competencies for Interprofessional Practice (Interprofessional Education Collaborative, 2016). Community clinical site experiences give students an upclose look at real team-based care in practice.

IPEP is intended to be an introduction to team-based care broadly, rather than a deep dive into any particular population or concern. Additionally, the experience focuses heavily on the process of team functioning rather than teaching disease-specific clinical knowledge and skills. The Behavioral Pediatrics course described in this paper builds on the tradition of interprofessional experiential learning at ETSU and extends the application of IPE core competencies (found in learning objective 3 below) to a pediatric population and with a focus on knowledge and skills needed to practically treat concerns presenting in the pediatric setting. In this way, the Behavioral Pediatrics course provides advanced training for students to apply skills learned in IPEP and builds on that experience.

\section{Existing University Infrastructure}

The ETSU Department of Pediatrics serves roughly 2000 to 3000 children per month through their General Pediatric division. Of patients serviced roughly $80 \%$ are insured through TennCare Medicaid (Polaha et al., 2018). Recognizing the importance of integrated care and aligning with the universities IPE efforts, ETSU Pediatrics and the ETSU Department of Psychology established a relationship to provide Behavioral Health services using doctoral psychology students under the supervision of a licensed psychologist. This collaboration originally began in 2009 with funding from an American Academy of Pediatrics Catch Grant. The Primary Care Behavioral Health model was and continues to be used to ensure a team-based approach to patient care (Polaha et al., 2016). The Department of Social Work began collaboration with ETSU Pediatrics in 2014 by placing a foundational year graduate-level social work intern to reach out to families in need of community resources. In 2015, the relationship with social work grew to include a part-time Licensed Clinical Social Worker to provide both care coordination and behavioral health and to supervise undergraduate and graduate social work interns completing their foundation and clinical placements. Behavioral health and social work services at ETSU Pediatrics proved to be such a need that currently ETSU Pediatrics have a full-time Psychologist, a full-time master's Level Social Worker, 2 doctoral psychology, and 1-2 social work students who are completing field hours. The Behavioral Health and Resource Team (BHART) sees roughly $15 \%$ of unique patients at the clinic each month.

\section{Course Creation and Enrollment}

The course, Behavioral Pediatrics: A Team Based Interprofessional Approach, was co-created by four faculty from three departments within ETSU: a pediatrician and a psychologist (Department of Pediatrics), a psychologist (Department of Psychology), and a doctoral-level social worker (Department of Social Work). This course was designed in response to a January 2019 call for proposals for Innovators in Interprofessional Curricula that was announced by ETSU's Interprofessional Education and Research Committee. The criteria required a new or re-designed IPE course specifically for students in health science professions needed to demonstrate a collaboration among departments. In addition to the stipend of $\$ 6000$ shared between collaborators, the Interprofessional Education and Research Committee provided support by being available for questions and helping with curriculum design and recruitment strategies. This course was limited to graduate students in the fields of psychology, social work, and medicine since each course collaborator was able to navigate listing the course in their respective departments and because each of these departments often has students rotating in outpatient pediatrics. The course was cross-listed in each of the three departments and enrolled 9 Clinical Psychology doctoral students, 4 third-year medical students, and 1 master's level social work student in the spring 2020 semester. The course met for three hours per week for fourteen weeks. The departments of each collaborator, while supportive of the interprofessional collaboration and course, did not adjust other teaching assignments. Therefore, facilitation was shared between the collaborators, rotating the need for presence at weekly class sessions. Teaching the course counted toward the collaborators' promotion and tenure criteria in the area of teaching innovation.

\section{Course Content and Format}

The course was developed to provide students with a broad understanding of how to work as part of an interprofessional team to assess and treat common behavioral health concerns presenting in pediatric primary care. Emphasis was placed on understanding how to intervene based on a biopsychosocial 
perspective. Interventions to address behavioral health and social determinants of health were emphasized from an integration of psychological, medical, and social work perspectives. The structure of the course was designed to be useful to students both within their discipline as well as in the practical care of pediatric patients. Behavioral interventions for common childhood complaints, as well as methods of teaching parents to alter family dynamics for the care of the patient were taught. Medical treatment, complications, and developmental contributions to these common presentations were emphasized. In addition to diagnosis-specific topics, the course focused on three systems of care that impact children: primary care, schools, and foster care/Department of Children's Services. Strategies to address social determinants of health were taught with a special emphasis on how addressing these concerns has advantages for both providers and patients within an integrated outpatient clinic setting. To emphasize both the practical and theoretical advantages of an integrated care approach, teaching occurred both in traditional lecture-based and case-based didactic format, as well as through simulated patient interactions. Core competencies for interprofessional practice (found in learning objective 3 below) were highlighted during these experiential components of the course.

Course topics varied by week and are listed in Table 1, along with selected references that formed the core-required readings for each week. Course learning objectives included

1. Learn and demonstrate evidence-based assessment and treatment for a wide array of behavioral and developmental concerns commonly found in pediatric primary care.

2. Learn typical/atypical development in infancy through adolescence and practice applying this knowledge to inform interventions with patients and families.

3. Apply Interprofessional Education Collaborative Core Competencies (values/ethics, roles/responsibilities, interprofessional communication, teams/teamwork) to behavioral pediatrics team-based assignments and standardized patient interactions.

4. Identify patients' social determinants of health and use this information to develop integrated treatment plans and link patients and families to relevant community resources.

5. Practice conceptualizing cases from a biopsychosocial perspective.

\section{Teaching Methods}

\section{Interactive Lectures}

Four faculty members from three professions (psychology, social work, medicine) rotated leading lectures, which typically lasted for $60 \mathrm{~min}$ of the three-hour class. During this time, faculty presented didactic material and led class discussions and reflections on assigned readings, as well as interprofessional team-based clinical case solving activities.

\section{Discussion Worksheet and Clinical Case Solving}

Prior to class, students used assigned readings to respond to a clinical case via a discussion worksheet. Responses to those cases were discussed via small group interprofessional teams during class.

\section{Fast Facts Reports}

In order to expand exposure to behavioral pediatrics content, students who missed a class were required to give a fiveminute "Fast Facts" at the following class, as a part of their make-up work. Fast Facts topics were chosen from a list of behavioral pediatrics topics not already covered in the syllabus. Student-generated resources related to the presentation were made accessible via a shared drive for the whole class to use. Topics included coping with grief/loss, children/adolescents with sexual behavior problems, school avoidance, medical procedures, diabetes, and pediatric headache.

\section{Simulations with Standardized Patients}

During nine out of the fourteen weeks, students participated in standardized patient (SP) encounters related to the topic of the week. These encounters took place in a technology-rich campus building dedicated to interprofessional education.

\section{Recruitment of Standardized Patients}

SPs were recruited from existing faculty and staff (and their children) in the department of Pediatrics. SPs were matched in age to the age of the prepared case presentation and pediatric SPs as well as their attendant caregivers were given a case to review (e.g., Fig. 1) and specific directions on how to present themselves (e.g., Fig. 2). Young children who participated were gifted a small bag of simple toys or art supplies of low monetary value as a thank-you. 


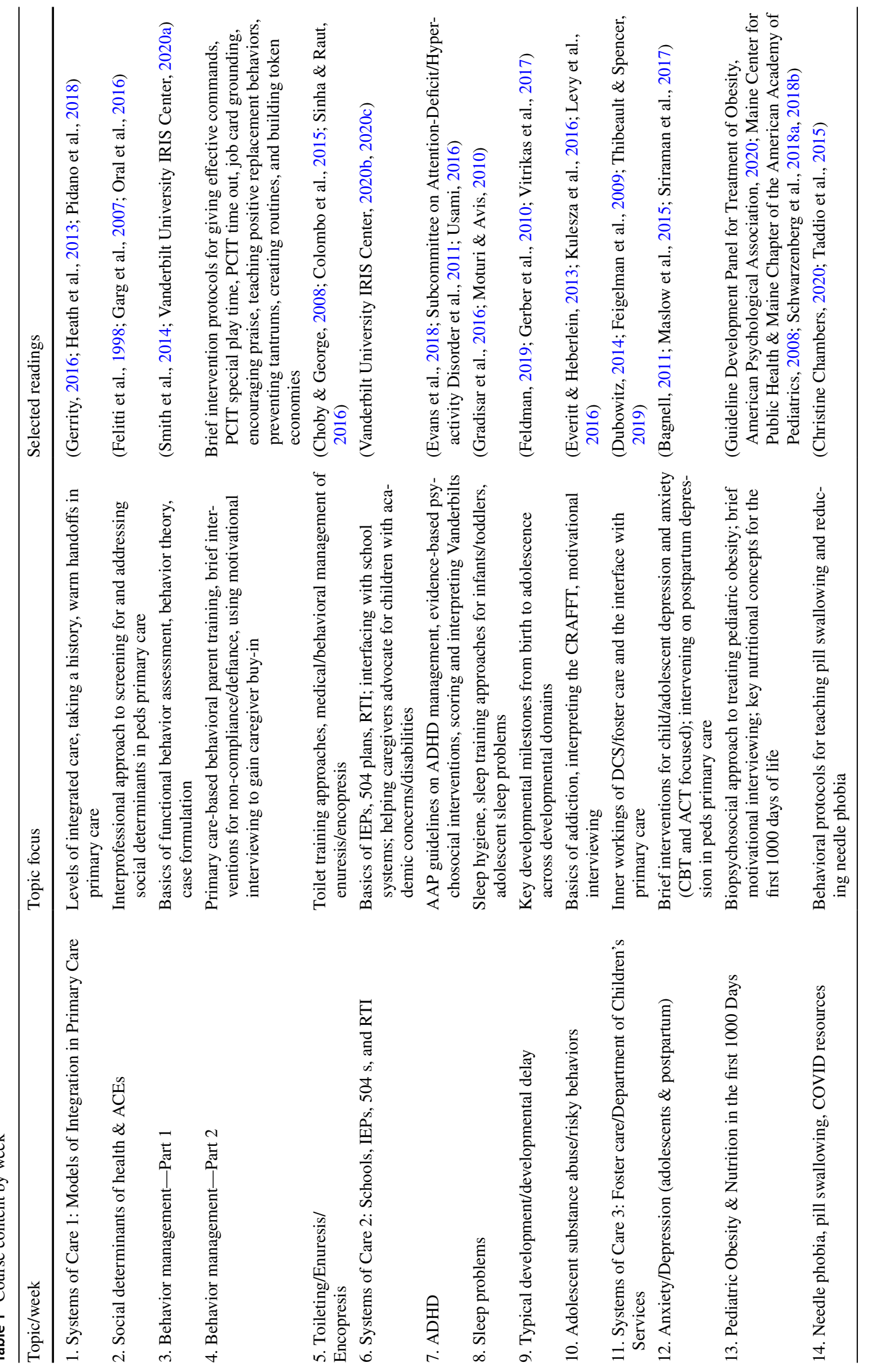


Samplease Notes for SPS

Initial visit Lindsey's mother was told by a teacher that (s)he needed to see a doctor and get some medication for ADHD. (S)he has trouble staying on task in class and will frequently wander off to other tables and interrupt classmates while they are working. Lindsey will occasionally talk back to the teacher, and has trouble following directions like staying in line to walk to other parts of the school. Lindsey has one teacher at school who teaches all the classes and this is a different teacher than last year.

Homework assignments often are not turned in, though Lindsey's mother does insist that she has ensured Lindsey completes all assignments at home. She checks on this by asking Lindsey on a daily basis what (s)he has or hasn't done and makes her finish all work after dinner in the living room while she catches up on the latest shows. She has talked with the teacher during both parent-teacher conferences this year and then at the phone call last week when she was told Lindsey needed medicine.

Last year Lindsey made "OK" grades in school but did tend to g"et in trouble "some (S)he was never suspended and passed the grade - level assessment provided by the state. On a general daily basis, Lindsey tends to wake at 7:15 AM and don clothing. (S)he usually skips breakfast and gets straight into the school bus which arrives at 7:25 AM. Lindsey gets out of school at 2:30PM and takes the bus home, where (s)he is met by her older cousin, who watches her/him until her mother gets out of work around 6 PM. They will typically eat around 7 PM, and Lindsey will play video games until bedtime in his/her bedroom. The mother thinks Lindsey usually falls asleep around 11 PM though it's hard to tell exactly because sometimes Lindsey leaves the TV volume in the bedroom up.

In terms of discipline, the mother generally will provide direction, and then use the counting technique to gradually raise tension and threats of spanking. Usually, she will get to around 2-and-a-half or 2-and-three-quarters and not have to spank the child. This probably happens every hour or so during the evenings.

They did have some issues with church, and Lindsey had to drop out of the children's choir after some issues with singing the wrong words routinely and interrupting services with inane commentary from the choir. Otherwise, things are going pretty well socially, and Lindsey has lots of friends.

Lindsey enjoys video games and texting with friends. Favorite foods are Mountain Dew and pizza. Lindsey wants to be a policeman.

Review of the medical record shows Lindsey has been a healthy child. No ongoing medical issues. Met developmental milestones. No family history except 2 older siblings with $\mathrm{ADHD}$ and mother with depression. Height/weight within normal limit at the 10 th percentile. No smoking in the house. 3 older siblings. 3 cats, no dogs in the house. Mother and cousin are primary caregivers, father does not stay in touch.

Follow- up visit: Hand the treatment team the attached Vanderbilt forms from you and school. Things are going a bit better, if the previous team suggested these interventions, you have made them:

- Homework completion rates have improved. Mother and teacher are talking every other day.

- Teacher still thinks the behavior/attention problems are severe enough to warrant medication though. You agree.

- Lindsey is doing better with sleep hygiene and scheduled bedtime.

- Teacher is completing daily report card and reinforcement system discussed at previous visit has been implemented with some behavioral success.

- Lindsey is exercising now a few days a week at least.

- Instead of counting and spanking you are doing time outs. Mostly.

- Lindsey has a quiet area to do homework in and is staying on task better.

- You have a meeting scheduled with the school to discuss behavioral accommodations.

- Lindsey is now drinking diet caffeine - free Mountain Dew.

- Positive feedback on good behavior seems to be working OK.

- If they didn't make those suggestions, you didn't do them yet.

If the treatment team suggests medicine, ask if there are any side effects, or anything you should be doing to make Lindsey tolerate the medication better. Also, ask if there are any other behavioral things you should be doing to help with Lindsey's behavior.

Fig. 1 Sample case notes for SPs

\section{Student SP Interviews and Debriefing}

Students were grouped into teams of 3-4, with at least two professions represented within each team. Teams interviewed SPs in mock primary care exam rooms, after briefly reviewing a case prompt (e.g., Fig. 3). Video technology in the exam rooms allowed the instructors and students not conducting the role play to observe these patient interactions in real time from a debrief room. Following the standardized role play, the student learners would move to the debrief room to receive feedback from the instructors, their peers, and the standardized patient on their role play. One to two faculty members would facilitate two teams, in a structure provided in Table 2. A three-phase debriefing procedure (reaction, analysis, summary) was used, consistent with established interprofessional clinical debriefing models (Rudolph et al., 2007).

\section{Assessment of Students}

Students were assessed through a variety of modalities (described below) designed to capture both academic and contextual knowledge and clinical acumen in assisting the standardized patients. Students were subjectively evaluated on participation in the class discussion of the weekly topic. They were given a discussion worksheet on this topic to assess knowledge of the pre-reading. Students were then assessed by faculty observing the standardized encounter and given immediate feedback on their performance with the patient and function as a multidisciplinary team.

\section{Student Feedback}

At the completion of the course, students were provided with a Student Assessment of Instruction (SAI). Students identified the following strengths for the course: resources (handouts/worksheets), applied learning with standardized patients, and the interprofessional components. Students expressed finding the resources we provided for behavioral topics throughout the semester very helpful and useful as they go into practice. One student stated, "One of the biggest strengths of this course was the applied learning aspect. I loved the fact that we were able to have standardized patients (SPs) at each class. Having SPs enabled us to use and integrate the information that we were being taught in the class!"

Three areas for growth were identified by students. First, medical students were graded on a pass/fail system due to the way the course was structured in the College of Medicine, but psychology and social work students were graded on an A-F system. Some psychology students felt that medical students were not as invested in the course 


\section{SP Presentation Notes}

\section{Instructions for Lindsey's mother}

Interact with treatment team as a parent. If the team gives advice on sleeping or discipline at home, inform them that you are here for medicine to make her act better at school and aren't as concerned about sleep or diet or exercise in an effort to prompt them to discuss the importance of behavioral consistency and lifestyle changes in the management of ADHD. Feel free to ad-lib. If Lindsey is disruptive, tell her to stop whatever (s)he is doing, and count slowly toward three in a very stern tone. At the follow-up visit, praise Lindsey for sitting still or not being disruptive occasionally.

\section{Instructions for Lindsey}

Don't sit still. Bump your leg up and down, or tap on the table, or talk about the shoes of one of the treatment team or tie your shoes. Be really friendly when they enter the room. Ask to borrow somebody's pen and click it open and closed rapidly until your mother takes it away. Try to interrupt the conversation every minute or so with a question that isn't related to the visit. Wander around the room once or twice. If your mother tells you to do something, ignore her until she starts counting and then go back to your seat and be quiet for a minute or so. If asked what you think the issue is at school say you get bored, or don't understand the classwork, or forget to bring in your homework. If asked when you go to sleep, say it changes from day to day. Your favorite class is science because you like blowing up gloves like balloons. Your least favorite class is reading because the teacher makes everybody sit and take turns reading paragraphs to the class and you forget where you are in the book, and everybody Laughs at you. At the follow-up visit, act a little quieter but still get distracted easily. Listen to your mother.

Fig. 2 SP presentation notes 
Fig. 3 Case prompt for team to review prior to SP interview
Case Prompt for Team to Review Prior to SP Interview

Chart: Lindsey Smith

Chief Complaint: School problems

Problem List: Otitis media (resolved), constipation (resolved), eczema, seasonal allergies

Past medical history: Healthy child

Past surgical history: None

Family history: ADHD (brother x 2)

Social history: Lives at home with mother, 3 brothers, 3 cats, no smoke exposure

NKDA

Height: $53 \mathrm{~cm}(12 \%)$

Weight: $34 \mathrm{~kg}(11 \%)$

Last BP: 99/56 (50\%)
Table 2 Structure of typical SP session

\begin{tabular}{|c|c|c|}
\hline Time & Group A & Group B \\
\hline $5 \mathrm{~min}$ & $\begin{array}{l}\text { Review case prompt with Group A and } \\
\text { determine initial plan of action }\end{array}$ & $\begin{array}{l}\text { Review case prompt with Group B and } \\
\text { determine initial plan of action }\end{array}$ \\
\hline $15 \mathrm{~min}$ & Assess SP and provide brief intervention & Observe Group A \\
\hline $5 \mathrm{~min}$ & Debrief with SP & Observe Group A debrief \\
\hline $10 \mathrm{~min}$ & Debrief as a larger group with faculty & \\
\hline $15 \mathrm{~min}$ & Observe Group B & Assess SP and provide brief intervention \\
\hline $5 \mathrm{~min}$ & Observe Group B debrief & Debrief with SP \\
\hline $10 \mathrm{~min}$ & Debrief as a larger group with faculty & \\
\hline Total: $65 \mathrm{~min}$ & & \\
\hline
\end{tabular}

as other students due to their pass/fail grade structure. Second, although students benefited from the simulated patients, some did not feel the need to have an experiential component each week. One student offered the idea of having an experiential class once a month and having 1.5-h blocks during the week for didactics. Lastly, it was expressed that the course might be better suited for 1 st- or 2nd-year graduate students rather than students who are already in their clinical concentration or field placements.

\section{Limitations and Strengths}

\section{Limitations}

Pulling together students from three different colleges within the university, all in various places within their program's curriculum, presented some challenges. During the semester, psychology students had internship interviews which led to absences and medical students had to end the course a few weeks early due to residency interviews. Only one social work student registered for the course, which was a reflection of the challenges for social work students to attend rather than level of interest. Since the course was offered in the spring semester, it did not align 
with full-time foundation or clinical students' curriculum sequence. For social work students it would have been advantageous to offer the course in an online environment and to offer the course to bachelor-level students who were planning to apply to the advanced standing program to pursue their clinical track. Another challenge presented by the multidisciplinary nature of the course was barriers to course offering presented by the medical school accreditation.

From a methodological standpoint, one significant limitation was the lack of formal pre- and post-assessment of knowledge, student satisfaction ratings, and more extensive qualitative feedback from students, perhaps even including thematic analysis of student qualitative feedback. At the time of course design, our focus was on pedagogy rather than research methodology, but in hindsight-improved metrics demonstrating student progression in IPE core competencies, general knowledge, and clinical skills would have been an asset.

\section{Impact of COVID-19 Pandemic}

On March 12, 2020 (approximately halfway through the course), university administration announced a move to virtual classes effectively immediately, in light of the worsening COVID-19 pandemic. Consequently, all meetings of this course following the university Spring Break were held via synchronous Zoom meetings. The format of the class proceeded much as usual; we met together for review of didactic material and then used the breakout room function on Zoom to conduct role plays with standardized patients. Naturally, the pivot to virtual learning presented some challenges, including instructors learning the Zoom platform and not being able to access on the ground facilities. However, the virtual learning format had benefits such as hosting guest speakers who may not have been able to attend otherwise and the Zoom platform oriented students in providing service via telehealth which may likely be a part of their jobs in the future.

\section{Strengths}

We designed the Behavioral Pediatrics: A Team Based Interprofessional Approach course to provide students in medicine in their 4th year and psychology and social work students in the clinical years with an opportunity to increase their skills in addressing behavioral issues of children and adolescents within a team-based environment. Highlights of the course that proved successful included the experiential component, focusing on the core competencies of Interprofessional Education (Interprofessional Education Collaborative, 2016), having a clinical, practical, and application-based focus and providing a toolbox of resources.
The experiential component of the course provided students with a chance to practice real-life roles during simulated patient interactions. Use of the University's Interprofessional Building proved very useful because of the use of the simulation rooms. The course accomplished not only introducing behavioral interventions but also reinforcing interventions and team-based approaches students may have touched on or learned in core course work. Many of the students in the course had previously completed a multidisciplinary communication class and this course built upon those skills in addition to introducing new concepts and patient problems. We believe future iterations of this course could even be scaled up, to an extent, and incorporate learners from additional disciplines. Offering the course online may be one way to accomplish this. Although the course design would need to consider a faculty-student ratio sufficient to provide personalized feedback to students during interactions with standardized patients, the structure of the class could likely accommodate up to 30 students per faculty member, given judicious use of small group interactions and peer-topeer feedback as appropriate. Our hope is that sharing this experience will encourage the wider creation and adoption of interprofessional courses with experiential components.

Author Contributions All authors made substantial contributions to the design of this work, drafted the work, approved the version to be published, and agreed to be accountable for all aspects of the work.

Funding Authors were awarded an internal university stipend to develop and teach the course described in this paper. No funding was received to assist with the preparation of this manuscript.

Data Availability Any data supporting this manuscript will be made available upon request.

Code Availability Not applicable.

\section{Declarations}

Conflict of interest Matthew Tolliver, Debi Thibeault, William Dodd, and Julia Dodd have no relevant financial or non-financial interests to disclose.

Ethical Approval Our university IRB determined that this proposed activity as described meets neither the FDA nor the DHHS definition of research involving human subjects. Therefore, it does not fall under the purview of the ETSU IRB.

Animal Rights No animals were used in this research.

Consent to Participate Not Applicable.

Consent for Publication Not Applicable. 


\section{References}

Asarnow, J. R., Rozenman, M., Wiblin, J., \& Zeltzer, L. (2015). Integrated medical-behavioral care compared with usual primary care for child and adolescent behavioral health: A meta-analysis. JAMA Pediatrics, 169, 929-937. https://doi.org/10.1001/jamapediatrics. 2015.1141

Bodenheimer, T., \& Sinsky, C. (2014). From triple to quadruple aim: Care of the patient requires care of the provider. Annals of Family Medicine, 12, 573-576. https://doi.org/10.1370/afm.1713

Feldman, H. M. (2019). How young children learn language and speech. Pediatrics in Review, 40, 398-411. https://doi.org/10. 1542/pir.2017-0325

Hine, J. F., Grennan, A. Q., Menousek, K. M., Robertson, G., Valleley, R. J., \& Evans, J. H. (2017). Physician satisfaction with integrated behavioral health in pediatric primary care. Journal of Primary Care \& Community Health, 8, 89-93. https://doi.org/10.1177/ 2150131916668115

Interprofessional Education Collaborative. (2016). Core competencies for interprofessional collaborative practice: 2016 Update. Washington, DC. https://hsc.unm.edu/ipe/resources/ipec-2016core-competencies.pdf. Accessed 1 July 2021.

Maine Center for Public Health \& Maine Chapter of the American Academy of Pediatrics. (2008). Keep me healthy flipchart: Pediatric obesity clinical decision support tool. https://cdn1.sph.harvard. edu/wp-content/uploads/sites/84/2012/09/Ped-Obesity-flip-chart_ Maine_FINAL.pdf. Accessed 1 July 2021.

McMillan, J. A., Land, M., \& Leslie, L. K. (2017). Pediatric residency education and the behavioral and mental health crisis: A call to action. Pediatrics. https://doi.org/10.1542/peds.2016-2141

Polaha, J., Click, I., Cross, B., Welch, A., Hess, R., \& Burchette, J. (2019). A mock job interview to assess an interprofessional education program. Journal of Interprofessional Education \& Practice, 15, 94-99. https://doi.org/10.1016/j.xjep.2019.03.001

Polaha, J., Dalton, W. T., \& Allen, S. (2011). The prevalence of emotional and behavior problems in pediatric primary care serving rural children. Journal of Pediatric Psychology, 36, 652-660. https://doi.org/10.1093/jpepsy/jsq116

Polaha, J., Schetzina, K., \& Baker, K. (2016). A collaborative practice training model for pediatric primary care. International Journal of Health Sciences Education, 3, 11.

Polaha, J., Schetzina, K. E., Baker, K., \& Morelen, D. (2018). Adoption and reach of behavioral health services for behavior problems in pediatric primary care. Families, Systems \& Health: THe Journal of Collaborative Family Healthcare, 36, 507-512. https://doi.org/ 10.1037/fsh0000380

Rudolph, J. W., Simon, R., Rivard, P., Dufresne, R. L., \& Raemer, D. B. (2007). Debriefing with good judgment: Combining rigorous feedback with genuine inquiry. Anesthesiology Clinics, 25, 361-376. https://doi.org/10.1016/j.anclin.2007.03.007

Schwarzenberg, S. J., Georgieff, M. K., Committee on Nutrition. (2018a). Advocacy for improving nutrition in the first 1000 days to support childhood development and adult health. Pediatrics. https://doi.org/10.1542/peds.2017-3716

Sokol, R., Austin, A., Chandler, C., Byrum, E., Bousquette, J., Lancaster, C., Doss, G., Dotson, A., Urbaeva, V., Singichetti, B., Brevard, K., Wright, S. T., Lanier, P., \& Shanahan, M. (2019). Screening children for social determinants of health: A systematic review. Pediatrics. https://doi.org/10.1542/peds.2019-1622

Walter, H. J., Vernacchio, L., Trudell, E. K., Bromberg, J., Goodman, E., Barton, J., Young, G. J., DeMaso, D. R., \& Focht, G. (2019). Five-Year outcomes of behavioral health integration in pediatric primary care. Pediatrics. https://doi.org/10.1542/peds.2018-3243

Williams, J., Klinepeter, K., Palmes, G., Pulley, A., \& Foy, J. M. (2004). Diagnosis and treatment of behavioral health disorders in pediatric practice. Pediatrics, 114, 601-606. https://doi.org/ 10.1542/peds.2004-0090

\section{Selected Course Readings from Table 1}

Bagnell, A. L. (2011). Anxiety and separation disorders. Pediatrics in Review, 32, 440-445. https://doi.org/10.1542/pir.32-10-440 quiz 446.

Choby, B. A., \& George, S. (2008). Toilet training. American Family Physician, 78, 1059-1064.

Christine Chambers. (2020). Pill swallowing and children. https://socie tyofpediatricpsychology.org/node/521. Accessed 1 July 2021.

Colombo, J. M., Wassom, M. C., \& Rosen, J. M. (2015). Constipation and encopresis in childhood. Pediatrics in Review, 36, 392-401. https://doi.org/10.1542/pir.36-9-392 quiz 402.

Dubowitz, H. (2014). The Safe environment for every kid (SEEK) model: Helping promote children's health, development, and safety: SEEK offers a practical model for enhancing pediatric primary care. Child Abuse \& Neglect, 38, 1725-1733. https:// doi.org/10.1016/j.chiabu.2014.07.011

Evans, S. W., Owens, J. S., Wymbs, B. T., \& Ray, A. R. (2018). Evidence-based psychosocial treatments for children and adolescents with attention deficit/hyperactivity disorder. Journal of Clinical Child and Adolescent Psychology: the Official Journal for the Society of Clinical Child and Adolescent Psychology, American Psychological Association, Division 53, 47, 157-198. https://doi. org/10.1080/15374416.2017.1390757

Everitt, B. J., \& Heberlein, U. (2013). Addiction. Current Opinion in Neurobiology, 23, 463-466. https://doi.org/10.1016/j.conb.2013. 07.003

Feigelman, S., Dubowitz, H., Lane, W., Prescott, L., Meyer, W., Tracy, J. K., \& Kim, J. (2009). Screening for harsh punishment in a pediatric primary care clinic. Child Abuse \& Neglect, 33, 269-277. https://doi.org/10.1016/j.chiabu.2008.09.011

Feldman, H. M. (2019). How young children learn language and speech. Pediatrics in Review, 40, 398-411. https://doi.org/10. 1542/pir.2017-0325

Felitti, V. J., Anda, R. F., Nordenberg, D., Williamson, D. F., Spitz, A. M., Edwards, V., Koss, M. P., \& Marks, J. S. (1998). Relationship of childhood abuse and household dysfunction to many of the leading causes of death in adults. The adverse childhood experiences (ACE) study. American Journal of Preventive Medicine, 14, 245-258. https://doi.org/10.1016/s0749-3797(98)00017-8

Garg, A., Butz, A. M., Dworkin, P. H., Lewis, R. A., Thompson, R. E., \& Serwint, J. R. (2007). Improving the management of family psychosocial problems at low-income children's well-child care visits: The WE CARE Project. Pediatrics, 120, 547-558. https:// doi.org/10.1542/peds.2007-0398

Gerber, R. J., Wilks, T., \& Erdie-Lalena, C. (2010). Developmental milestones: Motor development. Pediatrics in Review, 31, 267276. https://doi.org/10.1542/pir.31-7-267

Gerrity, M. (2016). Evolving models of behavioral health integration: Evidence update 2010-2015. https://www.milbank.org/publicatio ns/evolving-models-of-behavioral-health-integration-evidenceupdate-2010-2015/. Accessed 1 July 2021.

Gradisar, M., Jackson, K., Spurrier, N. J., Gibson, J., Whitham, J., Williams, A. S., Dolby, R., \& Kennaway, D. J. (2016). Behavioral interventions for infant sleep problems: A randomized controlled trial. Pediatrics. https://doi.org/10.1542/peds.2015-1486

Guideline Development Panel for Treatment of Obesity, American Psychological Association. (2020). Summary of the clinical practice guideline for multicomponent behavioral treatment of obesity and overweight in children and adolescents. The American Psychologist, 75, 178-188. https://doi.org/10.1037/amp0000530 
Heath, B., Wise Romero, P., \& Reynolds, K. (2013). A review and proposed standard framework for levels of integrated healthcare. SAMHSA-HRSA Center for Integrated Health Solutions.

Kulesza, M., Matsuda, M., Ramirez, J. J., Werntz, A. J., Teachman, B. A., \& Lindgren, K. P. (2016). Towards greater understanding of addiction stigma: Intersectionality with race/ethnicity and gender. Drug and Alcohol Dependence, 169, 85-91. https://doi.org/10. 1016/j.drugalcdep.2016.10.020

Levy, S. J. L., Williams, J. F., Committee on substance use and prevention. (2016). Substance use screening, brief intervention, and referral to treatment. Pediatrics. https://doi.org/10.1542/peds. 2016-1211

Maine Center for Public Health \& Maine Chapter of the American Academy of Pediatrics. (2008). Keep me healthy flipchart: Pediatric obesity clinical decision support tool. https://cdn1.sph.harvard. edu/wp-content/uploads/sites/84/2012/09/Ped-Obesity-flip-chart_ Maine_FINAL.pdf

Maslow, G. R., Dunlap, K., \& Chung, R. J. (2015). Depression and suicide in children and adolescents. Pediatrics in Review, 36, 299-308. https://doi.org/10.1542/pir.36-7-299 quiz 309-310.

Moturi, S., \& Avis, K. (2010). Assessment and treatment of common pediatric sleep disorders. Psychiatry (Edgmont (Pa.: Township)), 7, 24-37.

Oral, R., Ramirez, M., Coohey, C., Nakada, S., Walz, A., Kuntz, A., Benoit, J., \& Peek-Asa, C. (2016). Adverse childhood experiences and trauma informed care: The future of health care. Pediatric Research, 79, 227-233. https://doi.org/10.1038/pr.2015.197

Pidano, A. E., Arora, P., Gipson, P. Y., Hudson, B. O., \& Schellinger, K. B. (2018). Psychologists and pediatricians in the primary care sandbox: Communication is key to cooperative play. Journal of Clinical Psychology in Medical Settings, 25, 32-42. https://doi. org/10.1007/s10880-017-9522-y

Schwarzenberg, S. J., Georgieff, M. K., Committee on nutrition. (2018b). Advocacy for improving nutrition in the first 1000 days to support childhood development and adult health. Pediatrics. https://doi.org/10.1542/peds.2017-3716

Sinha, R., \& Raut, S. (2016). Management of nocturnal enuresismyths and facts. World Journal of Nephrology, 5, 328-338. https://doi.org/10.5527/wjn.v5.i4.328

Smith, J. D., Dishion, T. J., Shaw, D. S., Wilson, M. N., Winter, C. C., \& Patterson, G. R. (2014). Coercive family process and earlyonset conduct problems from age 2 to school entry. Development and Psychopathology, 26, 917-932. https://doi.org/10.1017/S0954 579414000169
Sriraman, N. K., Pham, D.-Q., \& Kumar, R. (2017). Postpartum depression: What do pediatricians need to know? Pediatrics in Review, 38, 541-551. https://doi.org/10.1542/pir.2015-0133

Subcommittee on Attention-Deficit/Hyperactivity Disorder, Steering Committee on Quality Improvement and Management, Wolraich, M., Brown, L., Brown, R. T., DuPaul, G., Earls, M., Feldman, H. M., Ganiats, T. G., Kaplanek, B., Meyer, B., Perrin, J., Pierce, K., Reiff, M., Stein, M. T., \& Visser, S. (2011). ADHD: Clinical practice guideline for the diagnosis, evaluation, and treatment of attention-deficit/hyperactivity disorder in children and adolescents. Pediatrics, 128, 1007-1022. https://doi.org/10.1542/peds. 2011-2654

Taddio, A., McMurtry, C. M., Shah, V., Riddell, R. P., Chambers, C. T., Noel, M., MacDonald, N. E., Rogers, J., Bucci, L. M., Mousmanis, P., Lang, E., Halperin, S. A., Bowles, S., Halpert, C., Ipp, M., Asmundson, G. J. G., Rieder, M. J., Robson, K., Uleryk, E.,,.. Bleeker, E. V. (2015). Reducing pain during vaccine injections: Clinical practice guideline. CMAJ: Canadian Medical Association Journal, 187, 975-982. https://doi.org/10.1503/cmaj.150391

Thibeault, D., \& Spencer, M. S. (2019). The Indian adoption project and the profession of social work. Social Service Review, 93, 804-832. https://doi.org/10.1086/706771

Usami, M. (2016). Functional consequences of attention-deficit hyperactivity disorder on children and their families. Psychiatry and Clinical Neurosciences, 70, 303-317. https://doi.org/10.1111/ pcn. 12393

Vanderbilt University IRIS Center. (2020a). Functional behavioral assessment: Identifying the reasons for problem behavior and developing a behavior plan. https://iris.peabody.vanderbilt.edu/ module/fba/. Accessed 1 July 2021.

Vanderbilt University IRIS Center. (2020b). IEPs: Developing highquality individualized education programs. https://iris.peabody. vanderbilt.edu/module/iep01/. Accessed 1 July 2021.

Vanderbilt University IRIS Center. (2020c). RTI (Part 1): An overview. https://iris.peabody.vanderbilt.edu/module/rti01/cr_assess/\#conte nt. Accessed 1 July 2021.

Vitrikas, K., Savard, D., \& Bucaj, M. (2017). Developmental delay: When and how to screen. American Family Physician, 96, 36-43.

Publisher's Note Springer Nature remains neutral with regard to jurisdictional claims in published maps and institutional affiliations. 